\title{
Erratum
}

\section{Myoglobin catalysis in lipid oxidation}

\section{Assay for activity with linoleic acid as substrate}

\section{Anni Mikkelsen, Laurette Sosniecki, and Leif H. Skibsted}

RVAU Center for Food Research and Chemistry Department, Royal Veterinary and Agricultural University, Thorvaldsensvej 40, DK-1871 Frederiksberg C, Denmark

The following errors occurred in the above article:

p.230, Fig. $2 \mathrm{~A}$; p.231, Fig. $4 \mathrm{~A} ;$ p.232, Fig. $5 \mathrm{~A}$ : The figures of the $y$-axis should be divided by 100 .

p.231, second column, I.10 should read: (res-)ponsible for only a minor fraction (less than $1 \%$ ) of the..

p.231, legend to Fig. 2, I.4-5 should read: $25.0^{\circ} \mathrm{C}$. Linear regression analyses gave $\mathrm{v}\left(\mathrm{O}_{2}\right)=0.1033( \pm 0.0052)+$ $0.0387( \pm 0.0015) \cdot[$ Tween 20$], \ldots$

p.232, legend to Fig. 5, I.4 should read: $\mathrm{v}\left(\mathrm{O}_{2}\right)=0.8993$ $( \pm 0.0114)-0.1160( \pm 0.0073) \cdot \mathrm{pH}$

p.232, Fig. 6A: 4.605 should be subtracted from the figures of the y-axis.

p.233, Table 2, third column: all figures should be divided by 100 .

Leif H. Skibsted 